\title{
Otimização da Metodologia para a Síntese do Composto Ácido 2-(4-alil-2-metoxifenoxi)acético
}

\author{
Chicon, M. C. ${ }^{1 *} ;$ Pinheiro, P. F. ${ }^{2}$ \\ 1 Graduação em Engenharia Química, Universidade Federal do Espírito Santo, Alegre, ES, Brasil. \\ 2 Departamento de Química e Física, Universidade Federal do Espírito Santo, Alegre, ES, Brasil.
}

*e-mail: marcello.ciciliote@gmail.com

\section{Resumo}

Os herbicidas são os pesticidas mais consumidos no Brasil, os quais são usados no controle de plantas daninhas, que são espécies indesejadas que causam prejuízos às lavouras. Devido aos problemas relatados para o uso dos agrotóxicos, existe uma demanda para a descoberta de novos herbicidas, sendo os compostos de origem natural e seus derivados (semissintéticos) opções viáveis, na obtenção de herbicidas, possivelmente, menos tóxicos. Como exemplo de composto natural, tem-se o eugenol, que é um fenol presente no óleo essencial de cravo-da-índia e que tem potencial no controle de plantas daninhas. Assim, o objetivo do presente trabalho foi otimizar as condições para a obtenção do ácido 2-(4alil-2-metoxifenoxi)acético, usando o eugenol como material de partida. Foram realizados 12 experimentos, onde foram avaliados os parâmetros: tempo, temperatura, solvente e quantidade dos reagentes. A estrutura do produto foi confirmada pela análise dos espectros de massas, $\mathrm{RMN}$ de ${ }^{1} \mathrm{H}$ e de ${ }^{13} \mathrm{C}$. Os rendimentos das reações foram obtidos por análise em cromatografia gasosa acoplada a detector por ionização em chama (CG-DIC) e variaram de 12,7 a 86,6\%. Esse melhor rendimento foi obtido usando a proporção de eugenol: cloroacetato de sódio (1:2), em água: acetona (4:1), na temperatura de $100{ }^{\circ} \mathrm{C}$ por $24 \mathrm{~h}$.

Palavras-chave: herbicidas, eugenol, plantas daninhas.

\section{Abstract}

Herbicides are the most consumed pesticides in Brazil. These are used in weed control, which are unwanted species that cause damage to crops. Due to the problems reported by the use of agrotoxics, there is a demand for the discovery of new herbicides which are less toxic. A new herbicide called semisynthetic has been discovered, and it can be produced by natural compounds. An example of a natural compound found in the herbicide is eugenol, a phenol existing in the clove essential oil that has a big potential for weed control. The objective of this work was to optimize the conditions for obtaining 2- (4allyl-2-methoxy) acetic acid using eugenol as a starting material.12 experiments were conducted to evaluated the parameters: time, temperature, solvent and quantity of reagents. The product structure was confirmed by mass spectral analysis, RMN of $1 \mathrm{H}$ and $13 \mathrm{C}$. The yields of the reactions were obtained by analysis in gas chromatography along with flame ionization detector (GC-FID) and ranged from 12,7 to $86,6 \%$. The best yield was obtained using the proportions of eugenol: sodium chloroacetate (1:2), water: acetone (4: 1) at a temperature of $100^{\circ} \mathrm{C}$ for $24 \mathrm{~h}$.

Keywords: herbicides, eugenol, weeds. 


\section{Blucher Proceedings \\ V SEMANA DE ENGENHARIA QUÍMICA UFES}

Blucher

\section{Introdução}

Os herbicidas ácidos constituem uma importante classe de pesticidas usados no controle de ervas daninhas, que são plantas indesejáveis nas lavouras, entre eles, alguns são derivados do ácido fenoxiacético. O ácido 2,4-diclorofenoxiacético (2,4-D) foi o primeiro herbicida seletivo bem sucedido, sendo introduzido em 1946 no mercado, transformando-se rapidamente no herbicida mais extensamente usado em todo o mundo. [1]

O Brasil, desde a década de 70, destaca-se como um dos maiores consumidores mundiais de pesticidas. Em abril de 2015, o Instituto Nacional de Câncer (INCA) divulgou um relatório sobre o uso de agrotóxicos nas lavouras do país e seus impactos sob o meio ambiente e à saúde do homem. Atualmente, o país ultrapassou a marca de 1 milhão de toneladas de agrotóxicos consumidos anualmente, o que equivale a um consumo médio de 5,2 kg de agrotóxico ao ano por pessoa. [2]

Para o agricultor, os agrotóxicos são recursos para combater as pragas, controlar o aparecimento de doenças e aumentar a produção, por isso são de suma importância nas lavouras. [3] Contudo, a aplicação de pesticidas gera, comumente, grandes problemas, devido serem tóxicos ao homem e animais, podendo ser cancerígenos, mutagênicos e teratogênicos. [4]

Outro problema relacionado ao uso excessivo de agrotóxicos são os sérios riscos ao meio ambiente, entre eles: a contaminação do solo, lençóis freáticos e rios, levando a morte de seres que vivem nesses locais. [5] Além disso, provocam na praga uma resistência cada vez maior a esses compostos devido o processo de seleção natural, o que leva à necessidade de usar doses maiores e produtos mais fortes, inviabilizando os herbicidas comumente utilizados. [6]

O uso de herbicidas sintéticos, embora seja considerado um método de controle eficaz para um número considerável de espécies de plantas daninhas, tem sido questionado quanto ao seus inúmeros impactos gerados no homem e meio ambiente. Portanto, a busca de herbicidas naturais e seus derivados (compostos semissintéticos) que não apresentem os inconvenientes dos herbicidas convencionais e que funcionem de maneira eficiente e acessível é de fundamental importância, visando minimizar o impacto causado por essas atividades. [7] Como exemplo, pode-se destacar o eugenol, composto natural que pode ser utilizado como material de partida para a obtenção do semissintético ácido 2-(4-alil-2metoxifenoxi)acético. [8] Esse ácido é análogo ao composto 2,4-D e tem grande potencial a ser usado como herbicida.

Além da obtenção de agrotóxicos a partir de compostos naturais, faz-se necessário a otimização destes processos, assim como nas demais sínteses orgânicas, buscando sempre o produto desejado com o máximo de conversão e seletividade, e com geração do mínimo de subprodutos e rejeitos. [9]

Com base nas informações citadas, este projeto tem como objetivo otimizar as condições reacionais para a síntese do composto ácido 2-(4-alil-2metoxifenoxi)acético modificando as variáveis da reação, tais como: tempo, temperatura, solvente e quantidade de reagentes, obtendo-se uma condição ótima para a síntese desse composto. No final do experimento foram usados métodos espectrométricos para confirmar a estrutura do ácido 2-(4-alil-2metoxifenoxi)acético.

\section{Materiais e Métodos}

Inicialmente, realizou-se a síntese do ácido 2(4-alil-2-metoxifenoxi)acético utilizando a metodologia descrita por Yan et al.,2014 com algumas adaptações (Esquema 1).

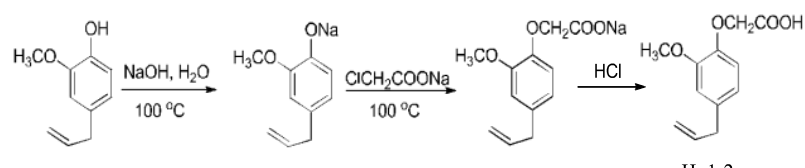

$\mathrm{pH} \sim 1-2$

Esquema 1: Etapas realizadas para obtenção do ácido 2-(4-alil-2metoxifenoxi)acético.

Primeiro, preparou-se uma solução de cloroacetato de sódio, para isso dissolveu-se o ácido 2cloroacético em solvente, água destilada ou acetona, e então resfriou-se a solução em banho de gelo. Em seguida adicionou-se $\mathrm{NaOH}$ sob agitação, até o pH ser ajustado em 9-10. 
Em seguida, usando um balão bitubulado de fundo redondo, foi preparado uma mistura de $\mathrm{NaOH}$, água destilada, acetona e eugenol. A referida mistura foi agitada por vinte minutos sob aquecimento a 100 ${ }^{\circ} \mathrm{C}$. Após os vinte minutos de aquecimento, o cloroacetato de sódio preparado previamente foi adicionado gota a gota. A solução reagente foi mantida sob aquecimento e deixada sob refluxo por 6h. Após o resfriamento à temperatura ambiente, o valor de $\mathrm{pH}$ da mistura foi acidificado para 1-2 com ácido clorídrico diluído, sob banho de gelo.

Para finalizar, realizou-se uma extração líquido-líquido, utilizando-se éter etílico para a separação das fases orgânica e aquosa, com o auxílio de um funil de separação. Na sequência, adicionou-se sulfato de sódio anidro a fase orgânica, com o intuito de extrair a água presente na solução, e então a mistura foi filtrada. A fase aquosa foi descartada adequadamente.

Ao final do processo, deixou-se a solução orgânica em repouso para que o éter utilizado anteriormente evaporasse, sobrando apenas 0 conteúdo de interesse (produto bruto).

O procedimento descrito acima representa o Experimento 1 da Tabela 1, ao todo foram realizadas 12 reações, com o intuito de se otimizar as condições, assim, foram variados: tempo (6h, 12h e 24h), temperatura (100 e $56{ }^{\circ} \mathrm{C}$ ), solvente (água e acetona) e quantidade de reagentes.

Tabela 1- Condições reacionais usadas na otimização da síntese do ácido 2-(4-alil-2-metoxifenoxi)acético

\begin{tabular}{|c|c|c|c|c|c|}
\hline \multirow[b]{2}{*}{ Exp. } & \multicolumn{2}{|c|}{ Equivalentes } & \multirow[b]{2}{*}{ Solvente } & \multirow[b]{2}{*}{$\mathbf{T}\left({ }^{\circ} \mathrm{C}\right)$} & \multirow[b]{2}{*}{$t(h)$} \\
\hline & Eugenol & $\begin{array}{c}\text { Cloroacetato } \\
\text { de sódio }\end{array}$ & & & \\
\hline 1 & 1 & 1 & $\begin{array}{l}\text { Água e } \\
\text { Acetona } \\
(80: 20)\end{array}$ & $100^{\circ} \mathrm{C}$ & $6 h$ \\
\hline 2 & 1 & 1 & $\begin{array}{l}\text { Água e } \\
\text { Acetona } \\
(80: 20)\end{array}$ & $100^{\circ} \mathrm{C}$ & $12 \mathrm{~h}$ \\
\hline 3 & 1 & 1 & $\begin{array}{l}\text { Água e } \\
\text { Acetona } \\
(80: 20)\end{array}$ & $100^{\circ} \mathrm{C}$ & $24 h$ \\
\hline 4 & 1 & 1 & $\begin{array}{c}\text { Acetona e } \\
\text { Água } \\
(80: 20)\end{array}$ & $56{ }^{\circ} \mathrm{C}$ & $6 h$ \\
\hline 5 & 1 & 1 & $\begin{array}{c}\text { Acetona e } \\
\text { Água } \\
(80: 20)\end{array}$ & $56{ }^{\circ} \mathrm{C}$ & $12 \mathrm{~h}$ \\
\hline 6 & 1 & 1 & Acetona e & $56^{\circ} \mathrm{C}$ & $24 h$ \\
\hline
\end{tabular}

\begin{tabular}{|c|c|c|c|c|c|}
\hline & 1 & 2 & $\begin{array}{c}\text { Água } \\
(80: 20)\end{array}$ & & \\
\hline 7 & 1 & $\begin{array}{c}\text { Água e } \\
\text { Acetona } \\
(80: 20)\end{array}$ & $100^{\circ} \mathrm{C}$ & $6 \mathrm{~h}$ \\
\hline 8 & 1 & 2 & $\begin{array}{c}\text { Água e } \\
\text { Acetona } \\
(80: 20)\end{array}$ & $100^{\circ} \mathrm{C}$ & $12 \mathrm{~h}$ \\
\hline 9 & 1 & 2 & $\begin{array}{c}\text { Água e } \\
\text { Acetona } \\
(80: 20)\end{array}$ & $100^{\circ} \mathrm{C}$ & $24 \mathrm{~h}$ \\
\hline 10 & 1 & $\begin{array}{c}\text { Acetona e } \\
\text { Água } \\
(80: 20)\end{array}$ & $56{ }^{\circ} \mathrm{C}$ & $6 \mathrm{~h}$ \\
\hline 11 & 1 & 2 & $\begin{array}{c}\text { Acetona } \mathrm{e} \\
\text { Água } \\
(80: 20)\end{array}$ & $56{ }^{\circ} \mathrm{C}$ & $12 \mathrm{~h}$ \\
\hline 12 & 1 & $\begin{array}{c}\text { Acetona } \mathrm{e} \\
\text { Água } \\
(80: 20)\end{array}$ & $56{ }^{\circ} \mathrm{C}$ & $24 \mathrm{~h}$ \\
\hline
\end{tabular}

O experimento 1 foi repetido. O ácido 2-(4-alil2-metoxifenoxi)acético foi purificado a partir desse por extração líquido-líquido com solventes quimicamente ativos, usando solução saturada de $\mathrm{NaHCO}_{3}$, seguida de acidificação com $\mathrm{HCl}$ (concentrado) sob banho de gelo. Foi obtido um sólido de cor bege claro.

O ácido 2-(4-alil-2-metoxifenoxi)acético, o eugenol (material de partida) e os produtos dos 12 experimentos realizados foram analisados por cromatografia gasosa acoplada ao espectrômetro de massas (CG-EM), em equipamento com detector seletivo de massa, modelo QP-PLUS-2010 (Shimadzu). A coluna cromatográfica utilizada foi a do tipo capilar de sílica fundida com fase estacionária Rtx-5MS, de $30 \mathrm{~m}$ de comprimento e 0,25 mm de diâmetro interno, utilizando hélio como gás de arraste. As temperaturas utilizadas foram de $250{ }^{\circ} \mathrm{C}$ no injetor e $300{ }^{\circ} \mathrm{C}$ no detector. A temperatura inicial da coluna foi de $120^{\circ} \mathrm{C}$, sendo programada para ter acréscimos de $10{ }^{\circ} \mathrm{C}$ a cada minuto, até atingir a temperatura máxima de 260 oC. Uma quantidade de $10 \mathrm{mg}$ do referido óleo essencial foi diluída em $1 \mathrm{~mL}$ de diclorometano, sendo injetado $1 \mu \mathrm{L}$ da mistura.

A substância foi caracterizada por espectrometria de massas, de RMN de ${ }^{1} \mathrm{H}$ e de ${ }^{13} \mathrm{C}$ em $\mathrm{CDCl}_{3}$.

Após a caracterização, foram obtidas soluções em diclorometano do ácido 2-(4-alil-2metoxifenoxi)acético nas concentrações: $4 \mathrm{mg} / \mathrm{mL}, 2$ $\mathrm{mg} / \mathrm{mL}, 1 \mathrm{mg} / \mathrm{mL}$ e $0,5 \mathrm{mg} / \mathrm{mL}$. Todas as soluções 


\section{Blucher Proceedings \\ V SEMANA DE ENGENHARIA QUÍMICA UFES}

Blucher

foram analisadas em um cromatógrafo a gás equipado com detector de ionização de chama (CG-DIC) CG2010 Plus (Shimadzu), usando a mesma coluna e as mesmas condições descritas anteriormente, e foi obtida uma reta de calibração.

Todos os produtos brutos dos experimentos (1 a 12) foram usados no preparo de soluções em diclorometano na concentração de $4 \mathrm{mg} / \mathrm{mL}$ e foram analisadas no mesmo cromatógrafo a gás equipado com detector de ionização de chama (CG-DIC), nas mesmas condições do ácido 2-(4-alil-2metoxifenoxi)acético purificado. Com a obtenção das áreas, foram calculados os rendimentos das reações.

\section{Resultados e Discussão}

O ácido 2-(4-alil-2-metoxifenoxi)acético obtido foi caracterizado por espectro de massas (Figura 1). Houve confirmação de sua formação pelo aparecimento do íon molecular em $\mathrm{m} / \mathrm{z}=222$.

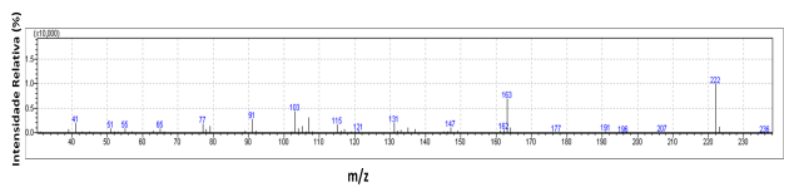

Figura 1: Espectro de massas do ácido 2-(4-alil-2-metoxifenoxi)acético.

Pelos espectros de RMN de ${ }^{1} \mathrm{H}$ (Figura 2) e de ${ }^{13} \mathrm{C}$ (Figura 3 ) foram observados todos os sinais que comprovam à formação do ácido 2-(4-alil-2metoxifenoxi)acético.

Os sinais dos hidrogênios em $\delta: 4,63$ ppm $\left(\mathrm{CH}_{2}\right)$ e em $\delta:$ 7,24 ppm confirmam que houve à formação do ácido 2-(4-alil-2-metoxifenoxi)acético, esses sinais não apareceriam no espectro do eugenol (material de partida) e estão de acordo com a literatura.

$\mathrm{O}$ espectro de RMN de ${ }^{13} \mathrm{C}$ para o ácido 2-(4alil-2-metoxifenoxi)acético apresentou os sinais dos carbonos do grupo ácido $(\mathrm{COOH})$ em $\delta: 172,83$ ppm e do $\mathrm{CH}_{2}\left(\mathrm{O}-\mathrm{CH}_{2}-\mathrm{COOH}\right)$ em $\delta: 67,17$ ppm, bem como todos os outros sinais esperados.

Nos cromatogramas obtidos 0 Eugenol (material de partida) apresentou tempo de retenção (TR) igual a 9,77 minutos e o ácido 2-(4-alil-2metoxifenoxi)acético (purificado) foi de 13,63 minutos.

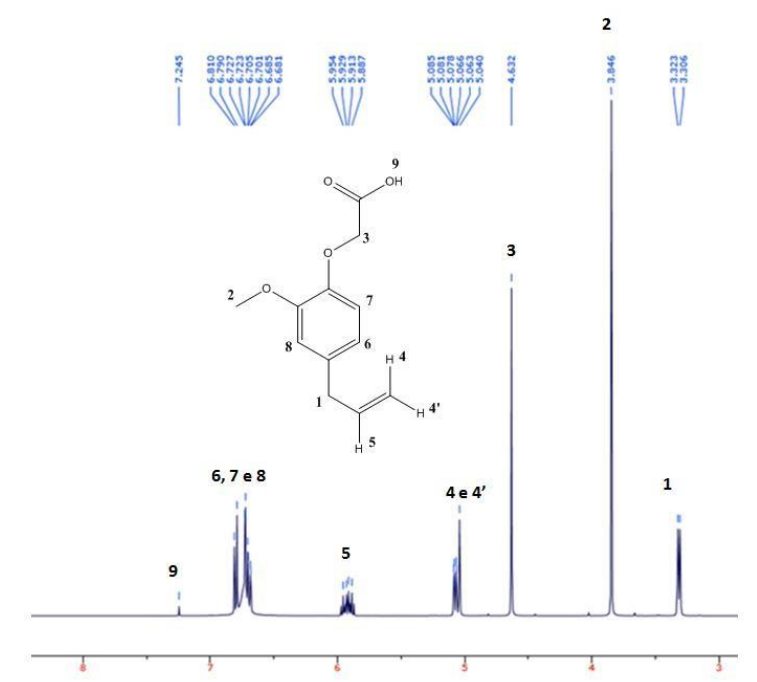

Figura 2: Espectro de $\mathrm{RMN}$ de ${ }^{1} \mathrm{H}\left(\mathrm{CDCl}_{3}\right)$ para o ácido 2-(4-alil-2metoxifenoxi)acético.

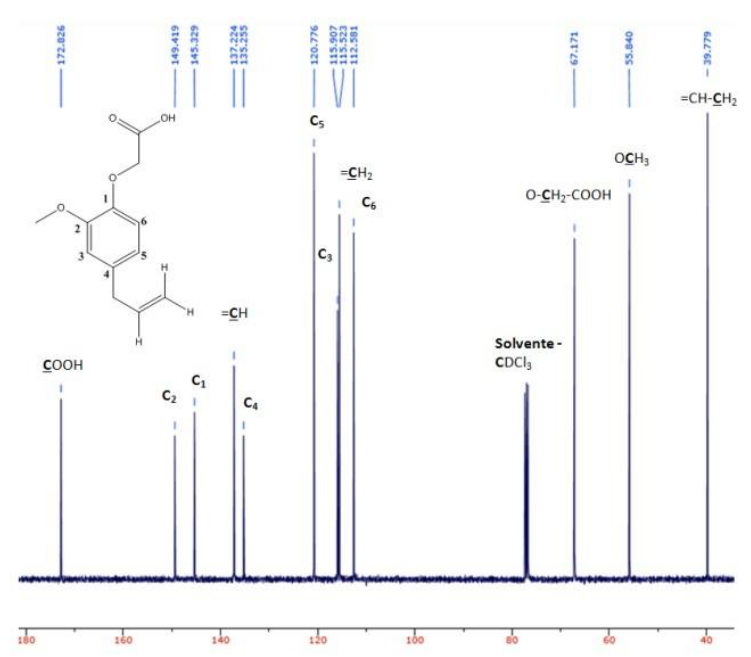

Figura 3: Espectro de $\mathrm{RMN}$ de ${ }^{13} \mathrm{C}\left(\mathrm{CDCl}_{3}\right)$ para o ácido 2-(4-alil-2metoxifenoxi)acético.

Os dados necessários para a obtenção da reta de calibração estão disponibilizados na tabela 2, enquanto que a reta está representada na figura 4.

Tabela 2. Dados para determinação da reta de calibração para determinação dos rendimentos das reações para obtenção do ácido 2(4-alil-2-metoxifenoxi)acético.

\begin{tabular}{c|c}
\hline Concentração $(\mathbf{m g} / \mathbf{m L})$ & Área $(\mathbf{C G})$ \\
\hline 4 & 1624808,1 \\
\hline 2 & 758500,7 \\
\hline 1 & 327051,1 \\
\hline 0,5 & 155999,9 \\
\hline 0 & 0 \\
\hline
\end{tabular}




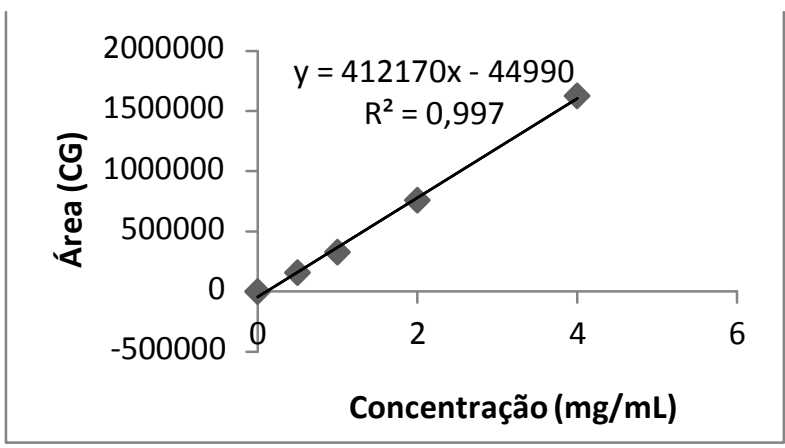

Figura 4. Gráfico da reta de calibração para determinação dos rendimentos das reações para obtenção do ácido 2-(4-alil-2metoxifenoxi)acético.

Utilizando-se as massas do produto final obtido com as respectivas quantidades de ácido presente em cada amostra, foi possível calcular o rendimento das reações, representado na tabela 3.

Tabela 3. Rendimentos da reação na obtenção do ácido 2-(4-alil-2-

metoxifenoxi)acético

\begin{tabular}{l|c|c|c}
\hline Amostras & $\begin{array}{l}\text { Massa } \\
\text { reação (g) }\end{array}$ & $\begin{array}{l}\text { Massa } \\
\text { Ácido(g)-CG }\end{array}$ & $\begin{array}{l}\text { Rendimento } \\
\text { (\%) }\end{array}$ \\
\hline Exp. 1 & 0,72 & 0,092 & 12,7 \\
\hline Exp. 2 & 0,81 & 0,183 & 22,6 \\
\hline Exp.3 & 0,73 & 0,310 & 42,5 \\
\hline Exp. 4 & 1,56 & 0,379 & 24,3 \\
\hline Exp.5 & 2,36 & 0,487 & 20,7 \\
\hline Exp.6 & 2,18 & 0,346 & 15,9 \\
\hline Exp.7 & 0,92 & 0,408 & 44,3 \\
\hline Exp. 8 & 0,91 & 0,633 & 69,5 \\
\hline Exp. 9 & 0,91 & 0,788 & 86,6 \\
\hline Exp.10 & 1,74 & 0,692 & 39,8 \\
\hline Exp.11 & 2,08 & 0,546 & 26,2 \\
\hline Exp.12 & 0,82 & 0,533 & 65,0 \\
\hline
\end{tabular}

O maior rendimento foi obtido na reação de número 9, utilizando-se água e acetona como solvente na proporção $4: 1$, temperatura de $100{ }^{\circ} \mathrm{C}$ e tempo de 24 horas.

\section{Referências}

[1] SBANO, A.; FERREIRA, J. V. R.; PECKLE, B. A.; MACRAE, A.; DIREITO, I. C. N. Otimização de Método Cromatográfico para Quantificação do Herbicida Ácido 2,4-diclorofenoxiacético (2,4-D). Acta Scientia \& Technicae, v.1, n.2, p.37-46, 2013.
[2] INCA (Instituto Nacional de Câncer). Posicionamento do Instituto Nacional de Câncer José Alencar Gomes da Silva Acerca dos Agrotóxicos. 06 de abril de 2015. Disponível em:< http://www1.inca.gov.br/inca/Arquivos/comunicacao/pos icionamento_do_inca_sobre_os_agrotoxicos_06_abr_1 5.pdf>. Acesso em: 17 jul. 2016.

[3] VEIGA, M. M. Agrotóxicos: Eficiência Econômica e Injustiça Socioambiental. Ciência \& Saúde Coletiva,v.12, n.1, p.154-152, 2007.

[4] CAETANO, M. S. Avaliação Teórica do Processo de Inativação do Herbicida Glifosato e Formação do 5Enolpiruvilchiquimato-3-fosfato (EPSP). 2011. $131 \mathrm{f}$. Tese (Doutorado em Agroquímica) - Programa de PósGraduação em Agroquímica, Lavras, 2011.

[5] GOMES, M. A. F.; BARIZON, R. R. M. Panorama da contaminação ambiental por agrotóxicos e nitrato de origem agrícola no Brasil: cenário 1992/2011. Jaguariúna, SP: Embrapa Meio Ambiente. (Documentos / Embrapa Meio Ambiente; 98), 2014.

[6] ChRISTOFFOLETI, P. J. ; OVEJERO, R. F. L.; CARVALHO, J. C. Aspectos de Resistência de Plantas Daninhas a Herbicidas. Associação Brasileira de Ação à Resistência de Plantas Daninhas - HRAC-BR, Campinas, BR, 2004.

[7] SOUZA FILHO, A. P. S.; SANTOS, R. A.; SANTOS, L. S.; GUILHON, G. M. P.; SANTOS, A.S; ARRUDA, M. S. P.; MULLER, A. H.; ARRUDA, A.C. Potencial Alelopático de Myrcia guianensis. Planta Daninha, v.24, n.4, p.649-656, 2006.

[8] MAZZAFERA, P. Efeito Alelopático do Extrato Alcoólico do Cravo-da-índia e Eugenol. Revista Brasileira de Botânica, v.26, n.2, p.231-238, 2003.

[9] MERAT, L. M. O. C.; SAN GIL, R. A. S. Inserção do Conceito de Economia Atômica no Programa de uma Disciplina de Química Orgânica Experimental. Química Nova, v.26, n.5, p.779-781, 2003. 